\title{
Stable isotope dilution techniques for assessing vitamin A status and bioefficacy of provitamin A carotenoids in humans
}

\author{
Harold C Furr ${ }^{1, *}$, Michael H Green ${ }^{2}$, Marjorie Haskell ${ }^{3}$, Najat Mokhtar ${ }^{4}$, \\ Penelope Nestel ${ }^{5}$, Sam Newton $^{6}$, Judy D Ribaya-Mercado7, Guangwen Tang ${ }^{7}$, \\ Sherry Tanumihardjo ${ }^{8}$ and Emorn Wasantwisut ${ }^{9}$ \\ ${ }^{1}$ Craft Technologies, 4344 Frank Price Church Road, Wilson, NC 27893, USA: ${ }^{2}$ Department of Nutritional \\ Sciences, Pennsylvania State University, University Park, PA, USA: ${ }^{3}$ Department of Nutrition, University of California, \\ Davis, CA, USA: ${ }^{4}$ International Atomic Energy Agency, Vienna, Austria: ${ }^{5}$ HarvestPlus, International Food Policy \\ Research Institute, Washington, DC, USA: ${ }^{6}$ Kintampo Health Research Center, Kintampo, Ghana: ${ }^{7}$ Jean Mayer US \\ Department of Agriculture Human Nutrition Research Center at Tufts University, Boston, MA, USA: ${ }^{8}$ Department of \\ Nutritional Sciences, University of Wisconsin, Madison, WI, USA: ${ }^{9}$ The Institute of Nutrition, Mahidol University, \\ Salaya, Thailand
}

Submitted 1 July 2004: Accepted 9 December 2004

\begin{abstract}
Vitamin A deficiency is a major global public health problem. Among the variety of techniques that are available for assessing human vitamin A status, evaluating the provitamin A nutritional values of foodstuffs and estimating human vitamin A requirements, isotope dilution provides the most accurate estimates. Although the relative expense of isotope dilution restricts its applications, it has an important function as the standard of reference for other techniques. Mathematical modelling plays an indispensable role in the interpretation of isotope dilution data. This review summarises recent applications of stable isotope methodology to determine human vitamin A status, estimate human vitamin A requirements, and calculate the bioconversion and bioefficacy of food carotenoids.
\end{abstract}

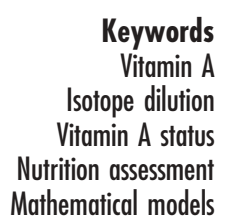

Nutrition assessment
Mathematical models
Vitamin A deficiency is a major public health problem in many parts of the world: over 131 million children of preschool age are vitamin A-deficient, and 4.4 million preschool children are afflicted with xerophthalmia ${ }^{1}$. Vitamin A is obtained from the diet as provitamin A carotenoids from fruit and vegetables, or as pre-formed retinyl esters from liver, eggs, dairy products or fortified foods. Vitamin A in excess of immediate requirements is stored as retinyl esters predominantly in the liver, although other tissues contain some stores. Vitamin A is released from the liver as retinol and transported in plasma by retinol-binding protein. The plasma concentration of retinol in the nutritionally adequate individual is tightly regulated by homeostatic mechanisms. Mathematical modelling (see below) indicates that vitamin A is extensively recirculated from extrahepatic tissues to the liver, and this system of storage and recirculation elegantly accommodates excesses of a potentially toxic nutrient while ensuring adequate amounts of retinol to all tissues during dietary insufficiency.

Human vitamin A status can be assessed by a variety of approaches: estimates of dietary intake; physiological indicators (night blindness); clinical signs (Bitot's spots, corneal damage); and biochemical indicators (plasma retinol concentration, liver vitamin A concentration, relative dose response (RDR), modified relative dose response (MRDR) and isotope dilution) (Table 1). Descriptive summaries of these techniques have been given by van Agtmaal et al. $^{2}$ and Tanumihardjo ${ }^{3}$. There are difficulties with the application and interpretation of each of these methods. Estimates of dietary intake are susceptible to the problems of estimating types and quantities of food consumed. Night blindness is a response to pronounced vitamin A deficiency; clinical signs may be due to other causes (i.e. lack specificity). Indicators using serum retinol concentrations have limitations because of the homeostatic control of serum retinol; and infection is known to depress serum retinol concentrations. Liver vitamin A concentrations can be obtained from autopsy specimens but are seldom available from living subjects. The one technique that potentially can give the most information about vitamin $\mathrm{A}$ status with least risk to the subject is isotope dilution. This approach was first applied by Rietz et al. ${ }^{4}$ and further developed by Rietz et $a l^{5}$ and Hughes et al. ${ }^{6}$. Various experiments using isotope dilution in animals and in humans were summarised by Bausch and Rietz ${ }^{7}$. Here we review studies that have developed, validated and applied 


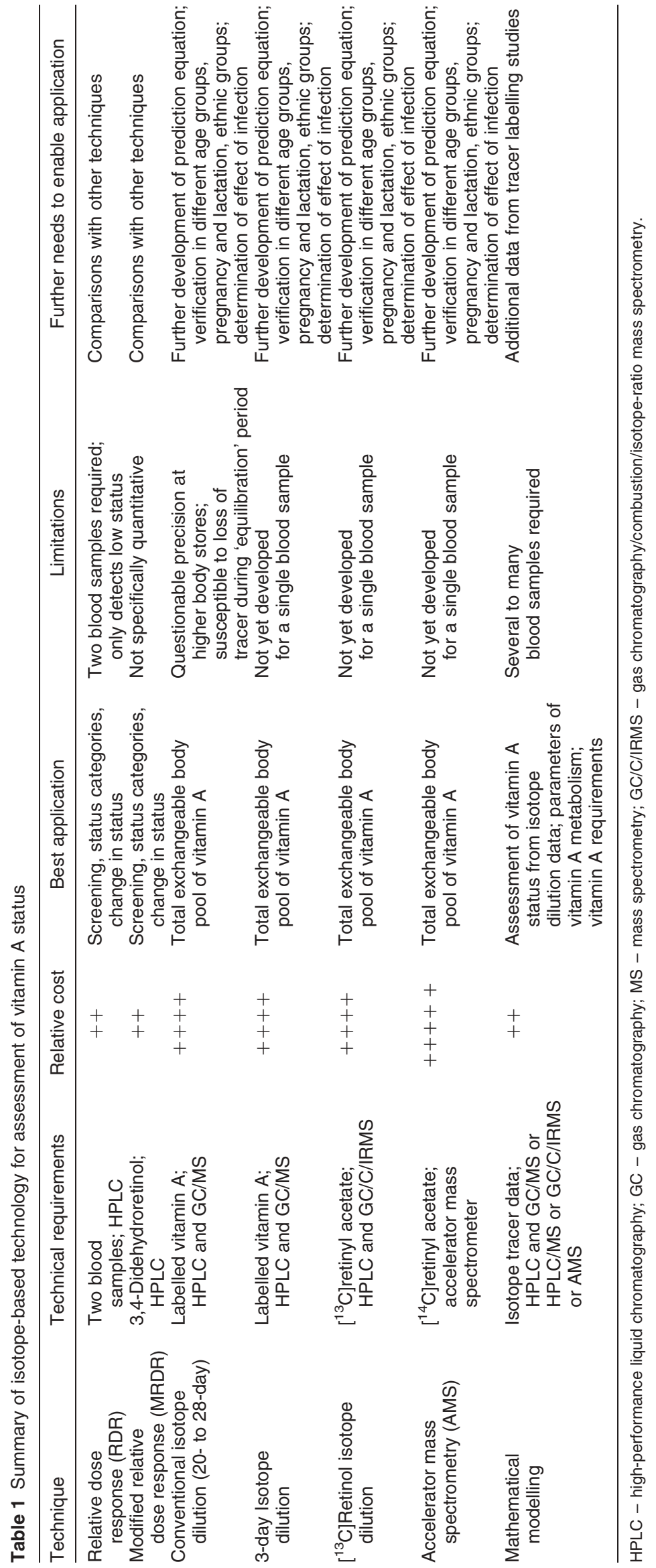


the isotope dilution method for assessing vitamin A status. Then we discuss the potential for expanding isotope dilution experiments so that sufficient data are acquired to enable the use of mathematical modelling to obtain information not only on vitamin A status, but also on other parameters related to vitamin A utilisation and dietary requirements.

The basic principle of isotope dilution is quite simple: a known quantity of tracer (radioactive or non-radioactive isotopically labelled vitamin A) is administered. The dose of labelled tracer needs to be ingested with adequate fat to ensure adequate absorption. After a suitable period for mixing of the tracer with the total-body vitamin A pool (unlabelled vitamin A, tracee), a plasma sample is taken and the ratio of tracer to tracee is measured. If the tracer mass is sufficiently small that it makes an insignificant contribution to the total mass, then

$$
\begin{aligned}
& \text { Specific activity }(1) \times \operatorname{mass}(1) \\
& =\operatorname{specific} \operatorname{activity}(2) \times \operatorname{mass}(2),
\end{aligned}
$$

where (1) refers to the tracer dose and (2) refers to the sum of tracer plus tracee after mixing.

Note that when a large dose of stable isotope-labelled 'tracer' is used, it makes a contribution to total mass and must be corrected for (see below); in such cases it may be argued that the labelled analogue is not a true 'tracer', but the principles of isotope dilution still apply and we shall maintain use of this term. (The limits of detection of the mass analyser ultimately determine the size of stable isotope dose that must be used.) Equation (1) indicates that the tracer/tracee ratio is greatest when total-body vitamin A pool size is low (vitamin A deficiency) and lowest when body pool size is large. The mathematical nature of the dilution response is such that, providentially, the greatest sensitivity is shown at the lowest amount of tracee (vitamin A deficiency). Sensitivity decreases as the amount of tracee (total-body vitamin A) increases (Fig. 1).

\section{Applying stable isotope dilution techniques}

Application of the isotope dilution technique in practice is complicated by the fact that in most free-living humans there is continuing intake of unlabelled vitamin A from the diet during the 'mixing period' between dosing and sampling. This results in dilution of the tracer/tracee ratio by increasing the amount of tracee while tracer is lost via catabolism. Thus, true 'equilibration' of the tracer with the tracee occurs at only one time, and it happens rather early after dosing; subsequently, the tracer/tracee ratio is parallel but not equal in plasma and other pools ${ }^{8}$. This is a point which is frequently misunderstood in indicatordilution techniques, but which must be taken into account in any model or prediction equation.

Simple mathematical models indicate that the percentage loss of tracer label to catabolism and that dilution by

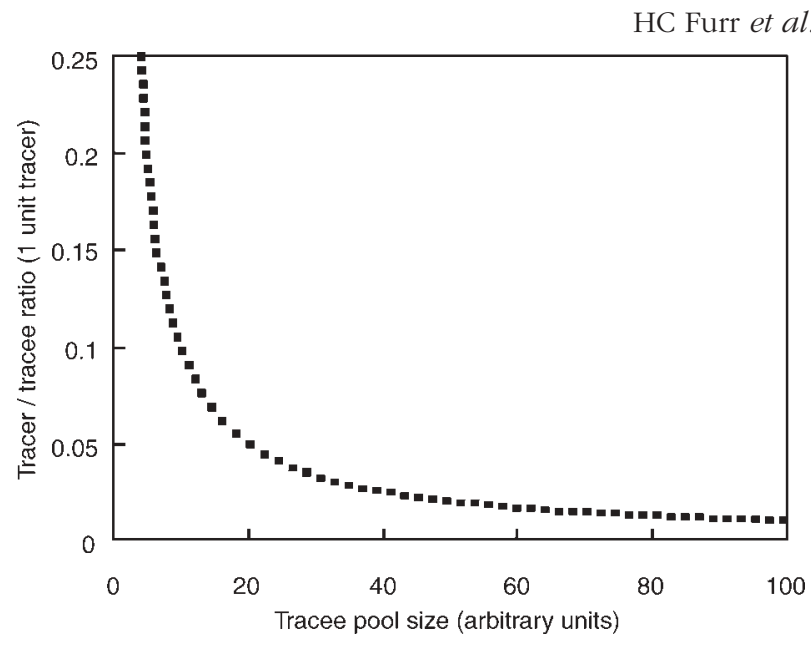

Fig. 1 Simple model of isotope dilution analysis: one unit of tracer (e.g. labelled vitamin A) is added to pools of various sizes of tracee (e.g. whole-body vitamin A) and allowed to mix thoroughly. Note that sensitivity (slope of the curve) is greatest at low tracee pool sizes (vitamin A deficiency)

(unlabelled) dietary vitamin A intake will be greatest when the vitamin A pool size (tracee) is low (i.e. the tracer/tracee ratio will decrease with time). Potentially, this could result in overestimation of vitamin A pool size if sampling is carried out too long after dosing with tracer. These aspects of isotope dilution have not been appreciated until recently, and early studies often used long 'equilibration' times. Bausch and Rietz ${ }^{7}$ observed a lower recovery of tracer in the liver of rats with poor vitamin A status than in vitamin A-replete rats; they attributed this to poorer efficiency of absorption. Simple models of vitamin A metabolism demonstrate that tracer is lost more quickly when total vitamin A stores are smaller (i.e. when the system fractional catabolic rate is larger) (HC Furr, unpublished observations).

Comparison of the isotope dilution approach for assessment of human vitamin A status with liver vitamin A concentrations was first done in a study conducted in well-nourished adult surgical patients by Professor James Olson and colleagues at Iowa State University. Application of the simple isotope dilution equation (equation (1)) gave very poor agreement between calculated (from isotope dilution data) and measured values (from liver biopsy specimens obtained at the time of surgery). Hence, Olson developed a modified isotope dilution equation' that is often referred to as the deuterated-retinol-dilution (DRD) technique:

$$
\begin{aligned}
& \text { Total-body vitamin A pool size } \\
& \quad=F \times \text { dose } \times(S \times a \times[(\mathrm{H}: \mathrm{D})-1]),
\end{aligned}
$$

where

$F=$ fraction of dose absorbed and retained (estimated to be 0.5$)$;

$S=$ ratio of specific activity of retinol in plasma to that in liver (estimated to be 0.65 ); 
$a=$ correction for loss of tracer via catabolism $\left[a=\mathrm{e}^{-k t}\right.$, where $k=\exp (0.693 / 140$ days $)$ and $t=$ days since dose]; assumed to be time-invariant and independent of vitamin A pool size;

$\mathrm{H}: \mathrm{D}=$ measured tracee/tracer ratio of plasma retinol; and $-1=$ correction for the contribution of the mass of tracer retinol to total-body vitamin A (this term is omitted when the mass of tracer is small compared with the mass of total-body vitamin A).

Application of this equation gave a much improved, albeit not perfect, correlation between calculated and measured stores. In a later study by Haskell et al. ${ }^{10}$, estimates of vitamin A pool size in Bangladeshi patients - as assessed by the DRD technique - were compared with estimates of liver vitamin A determined by direct measurement in liver biopsy specimens, obtained at the time of surgery, to determine whether the isotope dilution equation is valid in populations with low vitamin A pool sizes. A significant linear association was observed between the DRD and biopsy techniques (Fig. 2; $r=0.75, P<0.0001, n=30$ ), and the regression line did not differ from $y=x$ $(P=0.09)$. However, the $95 \%$ prediction interval for individual subjects was wide, indicating that the DRD technique does not provide a precise estimate of vitamin A pool size for individual subjects. (This interpretation is complicated by the heterogeneity of vitamin A concentrations in liver.) Nevertheless, the mean estimates of hepatic vitamin A based on the DRD and biopsy techniques were similar: $0.110 \pm 0.072 \mathrm{mmol}$ (range: $0.011-0.272 \mathrm{mmol}$ ) and $0.100 \pm 0.067 \mathrm{mmol}$ (range: $0.021-0.252 \mathrm{mmol})$, respectively $(P=0.27)$, indicating that the isotope dilution equation provides a good quantitative estimate of total-body vitamin A for groups of subjects with low to adequate vitamin A pool sizes.

Because the test dose of isotope was administered $\sim 10$ days before surgery, it was possible to estimate values for efficiency of storage of the test dose in liver and the ratio of

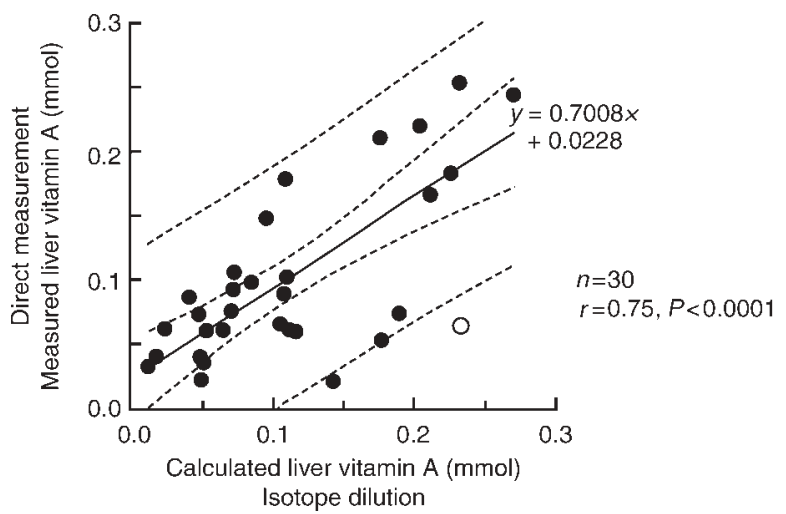

Fig. 2 Comparison of liver vitamin A determined by direct measurement or by isotope dilution technique in Bangladeshi adult surgical patients with low to adequate liver vitamin A stores (from Haskell et al. ${ }^{10}$ ). Reproduced with permission by the American Journal of Clinical Nutrition. (c) Am J Clin Nutr. American Society for Clinical Nutrition plasma-to-liver deuterium-labelled retinol to retinol in these patients, as described elsewhere ${ }^{10}$. Efficiency of storage of the test dose was estimated as $0.38 \pm 0.13$ (range: $0.18-0.72$ ), which differed from the value of 0.5 that is used in the isotope dilution equation $(P<0.0001)$. The mean value for the plasma-to-liver tracer/tracee ratio was estimated as $0.80 \pm 0.23$ (range: $0.38-1.21$ ), which differed from the value of 0.65 that is used in the isotope dilution equation $(P=0.003)$. However, the coefficients are multiplied together in the isotope dilution equation, resulting in a value of $0.325(0.5 \times 0.65$; equation (2)); the resulting value for the estimated coefficients in the Bangladeshi patients of $0.304(0.38 \times 0.80)$ did not differ from the value of $0.325(P=0.674)$. Thus, the coefficients that are used in the isotope dilution equation were not modified for estimating total-body vitamin A pool size in the Bangladeshi patients. In summary, the isotope dilution equation provided a good quantitative estimate of mean total-body vitamin A pool size for well-nourished surgical patients in the $\mathrm{USA}^{9}$ and for patients in Bangladesh with much lower vitamin A pool sizes ${ }^{10}$. Moreover, a subsequent study demonstrated that the DRD technique provides good quantitative estimates of change in vitamin A pool size in Bangladeshi adults in response to supplementation with different levels of vitamin $\mathrm{A}^{11}$.

To compare values of vitamin A reserves obtained by the isotope dilution procedure with values obtained by direct analysis of liver specimens from surgical patients in the two studies discussed above ${ }^{9,10}$, total-body vitamin A pool (in mmol) was converted to liver vitamin A concentrations (in $\mu \mathrm{molg}^{-1}$ ). Strictly speaking, totalbody vitamin A pool size is greater than the liver concentration, but it is generally assumed that liver contains more than $90 \%$ of total vitamin A in the wellnourished human ${ }^{12,13}$. Total vitamin A (as estimated by isotope dilution) is often approximated as liver vitamin A stores. To facilitate calculations, it is assumed that the liver weight/body weight ratio varies from 0.042 in infants to 0.024 in adults $^{13}$; the mean ratio of 0.03 has been used in older children. To define vitamin A adequacy, Olson ${ }^{13-15}$ estimated that a liver vitamin A concentration of at least $0.07 \mu \mathrm{mol} \mathrm{g} \mathrm{liver}^{-1}$ (20 $\mu \mathrm{g}$ g liver ${ }^{-1}$ ) would meet all physiological needs for the vitamin and would maintain a reserve for 3-4 months on low intakes or during periods of increased need due to infections and other stresses.

\section{Applications of isotope dilution analysis to assessment of human vitamin A status}

In recent years, the Olson isotope dilution equation (equation (2) or some modification of it) has been used to assess vitamin A status in a number of studies: children of pre-school age in Peru ${ }^{16}$; schoolchildren in China $^{17,18}$, Nicaragua ${ }^{19,20}$ and the USA ${ }^{21}$; young adults in Bangladesh ${ }^{10,11,21}$ and the USA ${ }^{9,21}$; and older adults in Guatemala $^{22,23}$ and the Philippines ${ }^{23,24}$ 
To examine whether vitamin A pool size affects 'equilibration time', an oral dose of deuterium-labelled retinyl acetate was administered to 24- to 36-year-old Bangladeshi and 31- to 44-year-old US adults and plasma retinol kinetics were plotted versus time after dosing ${ }^{21}$. 'Equilibration time' was estimated by fitting a biexponential equation to the observed plasma retinol kinetic data (Fig. 3) and was defined as the point at which 99\% of the fraction of dose in plasma was represented by the final exponential term. The mean 'equilibration times' were similar for US and Bangladeshi adults: $17.5 \pm 4.4$ and $16.3 \pm 3.9$ days, respectively $(n=4$ per group $)$ $(P=0.69)$. Thus, in both groups, the isotope dose mixed with endogenous vitamin A within 20 days post-dose. Using the plasma isotopic ratios of deuterium-labelled retinol/retinol at 20 days post-dose and the Olson isotope dilution equation (equation (2)), mean vitamin A pool sizes were estimated for the US and Bangladeshi adults as $1.03 \pm 0.45$ and $0.10 \pm 0.11 \mathrm{mmol}$, respectively $(P<0.01)$. Haskell and colleagues concluded that an oral dose of isotope mixes with endogenous vitamin A by $\sim 20$ days post-dose in adults and that 'equilibration time' is not affected by vitamin A pool size. Additionally, the fractional catabolic rate was estimated in these subjects as the coefficient of the final exponential term. The mean fractional catabolic rates for the US and Bangladeshi adults were $0.4 \% \mathrm{day}^{-1}$ (range: $0.1-0.7 \% \mathrm{day}^{-1}$ ) and $0.9 \% \mathrm{day}^{-1}$ (range: $0.5-1.2 \% \mathrm{day}^{-1}$ ), respectively. The fractional catabolic rate tended to be higher in the Bangladeshi subjects, but did not differ statistically from the rate for US adults or from the rate of $0.5 \% \mathrm{day}^{-1}$ that is used in the isotope dilution equation $(P>0.13)$. In 60- to 81-year-old elders in Guatemala, Ribaya-Mercado et $a .^{22}$ reported that an oral dose of deuterium-labelled vitamin A mixes with the endogenous vitamin A body pool within 20 days after isotope administration. Thus, the 'equilibration time' for young and older adults is similar.

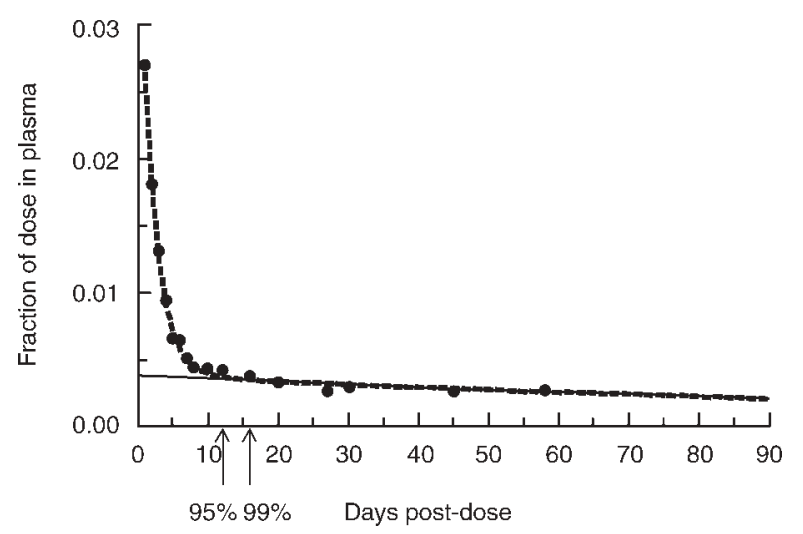

Fig. 3 Estimation of mixing time of tracer vitamin A with body vitamin A pools in Bangladeshi and US adult subjects (from Haskell et $a^{2}{ }^{21}$ ). Reproduced with permission by the American Journal of Clinical Nutrition. (c) Am J Clin Nutr. American Society for Clinical Nutrition
To determine whether the isotope dilution equation is valid for use in children, the plasma retinol kinetics of an oral dose of deuterium-labelled retinyl acetate were examined in 12- to 24-month-old Peruvian children by constructing a population-based plasma retinol kinetics curve to estimate 'equilibration time' and fractional catabolic rate ${ }^{16}$. The isotope dose mixed with endogenous vitamin A by 8 days post-dose, and the fractional catabolic rate was estimated as $2.2 \% \mathrm{day}^{-1}$ (95\% confidence interval: $1.4-3.0 \%$ day $^{-1}$ ) of the vitamin A pool. Vitamin A pool size was estimated for this population of children by using plasma isotopic ratios after 8 days post-dose. The Olson isotope dilution equation (equation (2)) was used, with an observed fractional catabolic rate of $2.2 \%$ day $^{-1}$ instead of the value of $0.5 \%$ day $^{-1}$ that is used for adults. The mean vitamin A pool size was estimated as $0.097 \pm 0.081 \mathrm{mmol}$. When expressed as $\mu \mathrm{molg}$ liver $^{-1}$, the estimated mean liver vitamin A concentration for this population was $0.310 \pm 0.259 \mu \mathrm{molg}^{-1}$ (median: $0.224 \mu \mathrm{mol} \mathrm{g}^{-1}$; range: $0.051-1.24 \mu \mathrm{mol} \mathrm{g}^{-1}$ ). This is within the range of values reported for liver vitamin A at autopsy for children aged 1-2 years in the USA $\left(0.273 \pm 0.150 \mu \mathrm{molg}^{-1} ; \quad\right.$ median: $\quad 0.227 \mu \mathrm{mol} \mathrm{g}^{-1}$; range: $\left.\quad 0.056-0.504 \mu \mathrm{molg}^{-1}\right)$ and Brazil $\left(0.120 \pm 0.100 \mu \mathrm{molg}^{-1}\right.$; median: $\left.0.098 \mu \mathrm{mol} \mathrm{g}^{-1}\right)$.

Ribaya-Mercado et al. ${ }^{24}$ investigated the vitamin A intakes of Filipino elders with adequate $(\geq 0.07 \mu \mathrm{molg}$ liver $\left.^{-1}\right)$ or low $\left(<0.07 \mu \mathrm{molg}_{\text {liver }}{ }^{-1}\right)$ liver vitamin $\mathrm{A}$ concentration, estimated by the DRD technique, to assess the dietary vitamin A requirements of elderly people. Mean total vitamin A intake (retinol activity equivalents (RAE)) of subjects with low estimated liver vitamin A was only about one-half that of subjects with adequate estimated liver vitamin A. Similarly, intakes of pre-formed vitamin A, $\beta$ carotene and $\alpha$-carotene were significantly higher in those with adequate than in those with low estimated liver vitamin A. Total-body vitamin A pool size correlated significantly with their dietary intakes of RAE, pre-formed vitamin A, $\beta$-carotene, fat and protein. In contrast, serum retinol concentration was unrelated to any of these dietary intakes. The investigators also found that men and women have similar vitamin A pool sizes when values are expressed per $\mathrm{kg}$ of body weight or per gram of liver (similar liver vitamin A concentrations $)^{24}$. This finding is consistent with the lack of a gender difference in vitamin A content of livers obtained at autopsies as reported by Raica et $a l .{ }^{12}$ and Hoppner et $a l .^{25}$. This application of isotope dilution calculations allowed Ribaya-Mercado et al. ${ }^{24}$ to estimate that an intake of dietary vitamin A of $6.45 \mu \mathrm{g}$ RAE $\mathrm{kg}$ body weight ${ }^{-1}$ is associated with adequate liver vitamin A; for a reference $76-\mathrm{kg}$ man and a reference 61-kg woman, these intakes are $\sim 500$ and $400 \mu \mathrm{g} \mathrm{RAE} \mathrm{day}^{-1}$, respectively.

Use of a short mixing time between administration of a labelled dose of retinol and blood sampling, instead of the conventional mixing time of 7-28 days, would be advantageous to increase subject compliance, decrease 
isotope dilution by dietary vitamin A and reduce loss of tracer via catabolism, thus improving the sensitivity of the assay. Studies by Adams and Green ${ }^{26}$ in rats indicated that it is possible to develop predictive equations for estimating body pools of vitamin A using an oral isotope dilution technique without the requirement of lengthy mixing of the isotope tracer with the body's vitamin A pool. This possibility was investigated in humans by Ribaya-Mercado et $a l^{22}$, who reported a significant correlation between total-body vitamin A pool (as estimated by the isotope dilution technique) and the ratio of deuterium-labelled retinol to retinol in serum 3 days after administration of an oral dose of deuterated retinyl acetate to Guatemalan elders. Subsequent studies in Filipino schoolchildren ${ }^{27}$ and elders ${ }^{23}$, Chinese schoolchildren ${ }^{18}$ and Peruvian children of pre-school age ${ }^{16}$ confirmed the usefulness of the shortened isotope dilution procedure for estimating total-body vitamin A pool size. Serum deuterium-labelled retinol/retinol ratios 3 days after an oral dose of deuterated retinyl acetate correlated better with estimated total-body vitamin A pools than serum deuterium-labelled retinol/ retinol ratios 6 days post-dosing with isotope in elders ${ }^{22}$. Early measurements were compared with a 21-day reference time by Tang et al. ${ }^{18}$ in schoolchildren. There was a significant correlation between the percentage enrichments of serum retinol with deuterated retinol at 3 and 21 days post-isotope-dosing, but no correlation was seen between percentage enrichments at $6 \mathrm{~h}$ and 21 days after the test isotope dose. Although equations from linear regression models are available for estimating total-body vitamin A pool size with the use of serum deuteriumlabelled retinol/retinol ratios at 3 days after an oral dose of deuterated retinyl $\operatorname{ester}^{16,18,22}$, these equations were derived by using post-equilibration serum retinol isotope data in the Olson equation' or a modification of that equation. The available 3-day DRD equations cannot be more sensitive than the equations from which they were derived. To formulate 3-day isotope dilution predictive equation(s) for vitamin A pool size that are independent of the assumptions inherent in the Olson equation, data for serum deuterium-labelled retinol/retinol ratios at 3 days after a test isotope dose and the corresponding hepatic vitamin A concentrations measured directly in liver specimens from the same subjects are needed for mathematical modelling.

Serum ratios of deuterium-labelled retinol to retinol at 3 days after a dose of deuterated retinyl acetate were used to determine the response of undernourished rural Filipino schoolchildren to a 12-week intervention study that provided lunch and two snacks rich in provitamin A carotenoids (orange fruit and vegetables) for 5 days of the week ${ }^{27}$. Using the 3 -day sampling protocol, there was a $55 \%$ decrease in serum deuterium-labelled retinol/retinol at the end of the intervention, indicating an improvement in vitamin A status. Thus, a 3-day DRD procedure can detect changes in body pool size of vitamin A in response to a fruit and vegetable intervention. This study also reported a strong inverse correlation between baseline vitamin A status of children and improvement in status in response to the intervention. Furthermore, a non-linear association was observed between serum deuteriumlabelled retinol/retinol ratios 3 days post-isotope-dosing and serum retinol concentrations. The association was stronger with serum retinol values $<0.70 \mu \mathrm{moll}^{-1}$ than with values $>0.70 \mu \mathrm{moll}^{-1}$. This finding is consistent with the concept that serum retinol concentration is under homeostatic control and tends to fall only when liver stores of vitamin A are low ${ }^{14}$

The DRD technique can reveal differences in the vitamin A status of populations that may not be evident with the use of serum retinol measurements. RibayaMercado et al. $^{23}$ have shown that the mean total-body vitamin A pool size in Guatemalan elders is about four times greater than that in Filipino elders ( 0.83 vs. $0.22 \mathrm{mmol}, P=0.0001$ ), and yet the mean serum retinol concentrations for these two groups are not significantly different (1.68 vs. $1.85 \mu \mathrm{moll}^{-1}, P=0.26$ ).

\section{Use of isotope dilution to estimate bioconversion and bioefficacy of carotenoids}

Of the over 600 carotenoids that have been identified in nature, only about 50 are precursors of vitamin A. Of these, the major provitamin A carotenoids in the human diet are $\beta$-carotene, $\alpha$-carotene and $\beta$-cryptoxanthin. The in vivo provitamin A value of these carotenoids from foods is dependent on a number of factors ${ }^{28}$ that have been characterised as bioaccessibility, bioavailability, bioconversion and bioefficacy ${ }^{29}$. Bioaccessibility is defined as the fraction of total dietary carotenoid made available for absorption in the gut. Bioavailability is defined as the fraction of dietary carotenoid absorbed from food. Bioconversion is defined as the ratio of retinol formed to total provitamin A carotenoid absorbed. Bioefficacy is defined as the ratio of retinol formed to the total provitamin A carotenoid in the diet.

Although the theoretical yield of retinol from $\beta$-carotene is 2:1 (and 1:1 for other provitamin A carotenoids), the measured bioconversion value is usually less. Factors associated with the dietary matrix (bioaccessibility) and with absorption (bioavailability) reduce the true bioefficacy of carotenoids in foods. This issue has considerable practical importance in assessing the true vitamin A value of diets and in planning public health interventions ${ }^{30,31}$, all the more so because of the lack of good animal models for human carotenoid metabolism. Conventional methods to estimate provitamin A carotenoid bioavailability are limited to the traditional methods of assessing vitamin A status. However, isotope dilution procedures provide a useful alternative for appraising the true provitamin A value of dietary carotenoids. An additional advantage is that they can be used to estimate provitamin A value of 
carotenoids in subjects who are not vitamin A-deficient (i.e. who show no change in serum retinol concentrations after consuming carotenoid-rich foods). Three different experimental approaches can be used:

1. estimate the total-body vitamin A pool size by dilution of labelled vitamin A tracer,

2. measure the dilution of isotope label arising from extrinsically labelled $\beta$-carotene, or

3. measure the isotope incorporation into body retinol from labelled carotenoid arising from intrinsically labelled foods ${ }^{32}$.

Haskell et al. ${ }^{33}$ compared the relative change in vitamin A pool sizes (by dilution of labelled vitamin A tracer) to estimate the vitamin A equivalency of carotenoids from several food sources in Bangladeshi men with low to adequate initial pool sizes. The $\beta$-carotene:retinol equivalence was estimated as 13.4:1 ( $\mu \mathrm{g} \beta$-carotene: $\mu \mathrm{g}$ retinol) for sweet potato, 9.5:1 for Indian spinach (Basella alba) and 6.3:1 for pure $\beta$-carotene in oil. Tang et al. ${ }^{17}$ measured the vitamin A pool size of Chinese school-aged children with low initial pool sizes before and after a food-based intervention using either green and yellow vegetables or light-coloured vegetables. In this study, the total-body vitamin A pools decreased in children who were fed lightcoloured vegetables but remained constant in children who were fed green and yellow vegetables. The calculated $\beta$-carotene:retinol equivalence was $26.7 \mu \mathrm{g} \beta$-carotene: $1 \mu \mathrm{g}$ retinol (range 19:1 to 48:1; molar ratio 14:1 with range $10: 1$ to $26: 1$ ). Parker et al. ${ }^{34}$ measured the dilution of deuterium-labelled retinol label by carotenoids from raw carrot in individuals with adequate pool sizes and estimated a mass equivalence of $13: 1$ ( $\mu \mathrm{g} \beta$ carotene: $\mu \mathrm{g}$ retinol). Tang et al. ${ }^{35}$ used intrinsic labelling of food carotenoids (carrots or spinach grown hydroponically in deuterated water) and compared the isotope ratio of carotenoid-derived retinol with that of an extrinsically labelled retinol tracer in adult human subjects. Using this approach, they estimated that the retinol equivalence of $\beta$-carotene from spinach was 29:1 ( $\mu \mathrm{g}$ $\beta$-carotene: $\mu \mathrm{g}$ retinol) and from carrot, 19:1 ( $\mu \mathrm{g} \beta$ carotene: $\mu \mathrm{g}$ retinol). This difference in equivalency of $\beta$-carotene from different plant food sources is attributed to the localisation of the carotenoid in the plant matrix. $\beta$ Carotene in spinach is located in chloroplasts ${ }^{36}$, whereas $\beta$-carotene in carrots is stored in chromoplasts ${ }^{37}$. The variation in the estimated bioconversion factors may perhaps be explained by the effect of initial vitamin A status of the subjects; food preparation techniques that may have resulted in provitamin A losses and/or transformation of the more bioavailable trans isomers to cis forms; and (in some cases) the presence of intestinal parasites.

Other groups have used synthetic $\left[{ }^{13} \mathrm{C}\right]$ retinol and $\beta$-carotene to determine the bioefficacy of small doses administered over time to children ${ }^{38,39}$. van Leishout et $a l .{ }^{40}$ analysed the faeces of children who were given an extrinsic isotopic label at the same time as pumpkin or spinach. The conclusions from the faecal analysis were consistent with those from serum analysis, that $\beta$-carotene from pumpkin is more bioavailable than that from spinach. Edwards et al $^{41}$ used deuterium-labelled retinyl acetate as an extrinsic reference to estimate the bioefficacy of conversion of food $\beta$-carotene to retinol.

Studies on the absorption of uniformly labelled $\left[{ }^{13} \mathrm{C}\right]$ carotenoids include those of Yao et $a l^{42}$ on lutein and Parker et al $^{43}$ on $\beta$-carotene isolated from algae grown in a ${ }^{13} \mathrm{CO}_{2}$ environment. Kelm et al. ${ }^{44}$ and Kurilich et $a l^{45}$ have studied absorption and metabolism of lutein and $\beta$-carotene derived from kale labelled with ${ }^{13} \mathrm{CO}_{2}$. Alternatively, intrinsically labelled foodstuffs have been prepared by growing spinach or collard greens in ${ }^{2} \mathrm{H}_{2} \mathrm{O}^{46}$.

\section{Technical aspects of isotope dilution analysis}

There is strong opposition to the use of radioactive isotopes as tracers in human subjects. Therefore, stable isotope labels (heavy atoms, ${ }^{2} \mathrm{H}$ or ${ }^{13} \mathrm{C}$ ) have been used for vitamin A isotope dilution studies, and mass spectrometry is used to determine tracer/tracee ratio. The natural abundance of ${ }^{13} \mathrm{C}$ (1.1\% of total carbon atoms) necessitates that at least three, and preferably four, heavy atoms be incorporated in the tracer vitamin A molecule to avoid isotopic contribution by naturally occurring ${ }^{13} \mathrm{C}$. In practice, gas chromatography has been used to introduce the vitamin A to the mass spectrometer. Plasma retinol is extracted and purified by high-pressure liquid chromatography, and the retinol fraction is collected and derivatised to facilitate gas chromatography ${ }^{47}$. Conventional electron-impact ionisation mass spectrometry requires relatively large amounts of tracer for satisfactory quantification of the isotope ratio in retinol in human isotope dilution studies (doses of 30 to $155 \mu \mathrm{mol}$ in adults). Chemical ionisation mass spectrometry improves the limits of detection, allowing use of smaller doses of $\operatorname{tracer}^{18,48}$. The newer, alternative technique of gas chromatography/combustion/isotope-ratio mass spectrometry (GC/C/IRMS) provides sensitivity at least 10 times greater than that of conventional gas chromatography/mass spectrometry ${ }^{49}$. Tanumihardjo ${ }^{3,50}$ has shown that much smaller physiological doses of $\left[{ }^{13} \mathrm{C}\right]$ retinol tracer can be used effectively when GC/C/IRMS is employed for analysis; thus the mass of tracer is small enough to not perturb vitamin A metabolism in the subject.

Recently, the extremely sensitive technique of accelerator mass spectrometry (AMS) has been developed for analysis of $\left[{ }^{14} \mathrm{C}\right] \mathrm{retinol}{ }^{51,52}$. The dose necessary for tracer studies is in the $\mu \mathrm{g}$ range, and as little as $30 \mu \mathrm{l}$ of serum is required for determination of the tracer/tracee ratio. Such small doses completely avoid problems of perturbing tracee pools of vitamin A or of introducing potentially harmful amounts of radioactivity. However, AMS is quite 
expensive to implement, thus limiting its potential applications. Although the exposure to radiation is quite low (less than that of a single transcontinental flight), the use of radioactive tracers may not be acceptable for all subjects, especially young children and pregnant women.

\section{Extending isotope dilution analysis through mathematical modelling}

All of the isotope dilution procedures discussed above require administration of isotopically labelled retinol or provitamin A and all require collection of blood samples from study participants. Typically, the information obtained is limited to estimation of vitamin A stores; sometimes other parameters such as fractional catabolic rate or equilibration time are also calculated. If additional blood samples are obtained from subjects, it is possible to apply the techniques of model-based compartmental analysis to these studies and thus obtain other very useful information about vitamin A utilisation, dietary requirements and other aspects of whole-body vitamin A metabolism.

To develop a compartmental model for vitamin A metabolism ${ }^{53,54}$, a tracer (stable or radioactive) is administered to the experimental animals or human subjects, plasma samples collected over time are analysed for tracer, and data on the fraction of dose in plasma versus time are analysed using software such as the Simulation, Analysis and Modeling (SAAM) computer program ${ }^{55,56}$. This approach has been used to develop models of wholebody vitamin A metabolism in rats at different levels of vitamin A status ${ }^{57,58}$. Based on the extent of the data collected and on what is currently known about wholebody vitamin A metabolism, a compartmental description of the system can be formulated (Fig. 4). Different compartments correspond to vitamin A in different physical spaces or with differing kinetic behaviour. Compartments 1 to 4 describe the processes of absorption of the isotopic dose of vitamin $\mathrm{A}$, the metabolism of retinyl esters in chylomicrons, the liver uptake of chylomicron remnants and their metabolism, and the subsequent secretion of retinol bound to retinol-binding protein from hepatocytes into plasma compartment 11. Compartments 12 and 13 are extravascular pools of vitamin A; one (compartment 12) comprises fast turning-over pools while compartment 13 includes slower turning-over vitamin A such as that in liver stores.

Figure 5 shows the plasma response curve for octadeuterated retinol over a 52-day experimental period following oral administration of octadeuterated retinyl acetate to a 67-year-old female subject studied by Tang et $a l^{59}$ and Wang et al. ${ }^{60}$. After absorption was complete, the geometry of the plasma response curve was similar to that observed in rats $^{57,58}$. The initial rapid decline in isotope ratio is due to vitamin A moving out of plasma (compartment 11) into compartments 12 and 13. As the

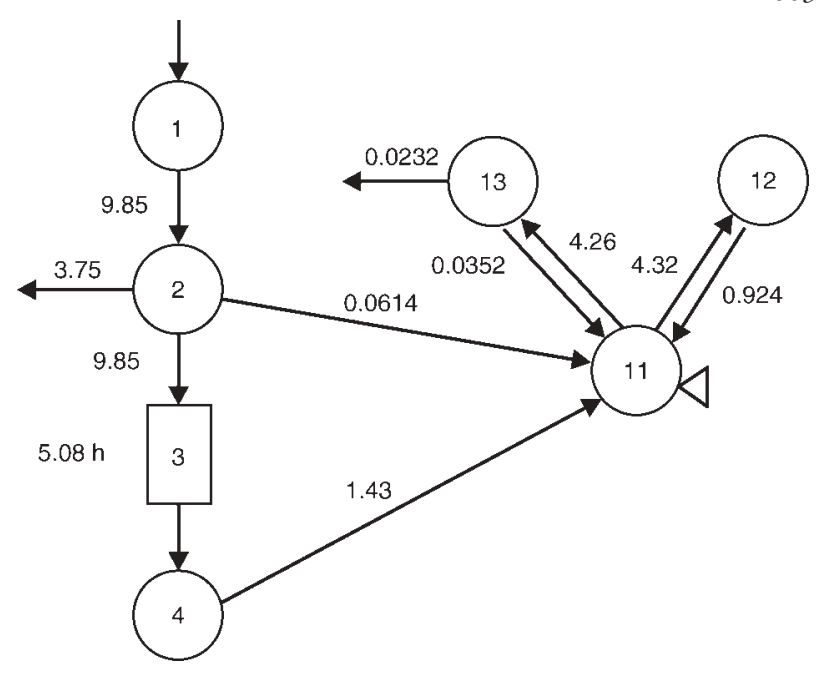

Fig. 4 A multicompartment model of human vitamin A metabolism. Compartments 1 to 4 describe the processes of absorption of the isotopic dose of vitamin A, the metabolism of retinyl esters in chylomicrons, the liver uptake of chylomicron remnants and their metabolism, and the subsequent secretion of retinol bound to retinol-binding protein from hepatocytes into plasma compartment 11. Compartments 12 and 13 are extravascular pools of vitamin $A$; one (compartment 12) comprises fast turning-over pools while compartment 13 includes slower turning-over vitamin A such as that in liver stores. Numbers beside arrows indicate fractional transfer coefficients between compartments

tracer mixes in these pools, it begins to recycle to plasma, slowing down the tracer disappearance from plasma. Once mixing is complete, the plasma response profile comes into a terminal slope that is a function of the system fractional catabolic rate for vitamin A.

These data on the fraction of ingested dose of octadeuterated retinol remaining in plasma versus time were analysed using WinSAAM, the Windows version of the SAAM program ${ }^{56}$. Model parameters (fractional transfer coefficients, or the fraction of the pool of vitamin A per day transferred between linked compartments) were iteratively adjusted until a concordance was obtained between the observed data and model-predicted values. The fractional transfer coefficients describing movement of vitamin A among compartments for this subject are shown in Fig. 4. The fractional absorption of retinol was fixed at $72.5 \%$. Concentrating on the post-absorptive

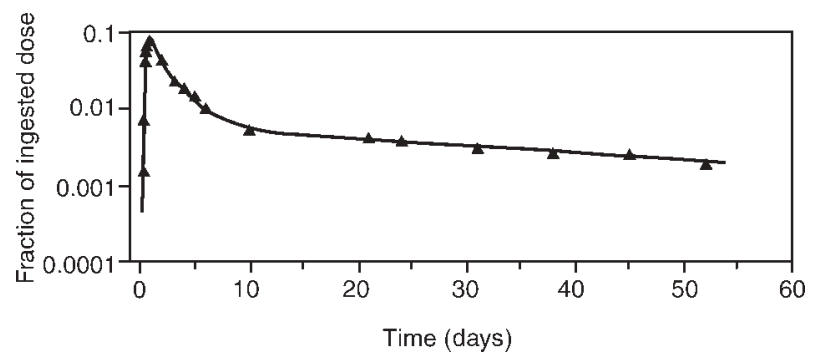

Fig. 5 Plasma response curve for octadeuterated retinol following oral administration in a human subject. Triangles indicate experimental data (Tang et al. ${ }^{59}$ ); the solid line represents the predicted behaviour from the multicompartment model shown in Fig. 4 
metabolism of retinol, the model predicts that retinol is secreted from compartment 4 (representing hepatocytes) into plasma compartment 11 at a rate of 1.43 pools day ${ }^{-1}$. Once retinol enters plasma, it remains for approximately $2.8 \mathrm{~h}$ before moving into the fast turning-over extravascular compartment 12 at $\sim 4.3$ pools day ${ }^{-1}$. Vitamin A moves into the slower turning-over compartment 13 (that includes liver stores of the vitamin) at approximately the same fractional rate. From the fast turning-over extravascular compartment $12, \sim 1$ pool day ${ }^{-1}$ returns to plasma. From the slower turning-over compartment 13, less than $4 \%$ of the pool day ${ }^{-1}$ moves into compartment 11 , and $\sim 2 \%$ day $^{-1}$ is irreversibly lost. That is, the system fractional catabolic rate indicates that about 0.02 pools of body vitamin A are being irreversibly used each day. By knowing the plasma retinol concentration, as well as an estimate of the plasma volume, the mass of retinol in the plasma pool $(5.3 \mu \mathrm{mol}$ for this subject) can be calculated. Applying a steady-state solution using WinSAAM, estimates for compartment sizes and transfer rates as well as the total liver reserves or the total exchangeable pool of vitamin A in her body can be determined. Adding the masses for compartments 11, 12 and 13 gives an estimate of the total traced mass of $417 \mu$ mol. The vitamin A disposal rate (loss from compartment 13) was estimated to be $9 \mu \mathrm{mol} \mathrm{day}{ }^{-1}\left(2.6 \mathrm{mg} \mathrm{day}^{-1}\right)$ for this presumably wellnourished individual. By applying an estimate of the fractional absorption of vitamin A to this value, the daily intake of vitamin $\mathrm{A}\left(12.4 \mu \mathrm{mol} \mathrm{day}{ }^{-1}\right.$ or $\left.3.6 \mathrm{mg} \mathrm{day}^{-1}\right)$ can be calculated. In addition to these parameters, mean transit times (the length of time the vitamin stays on average in a particular compartment from the time of entry until the time of exit from that compartment), residence times (the total time the vitamin spends in a particular compartment from the time it first enters until it leaves irreversibly), recycling number for plasma (number of times the vitamin recycles to plasma before being irreversibly utilised) and recycling time (length of time on average before a vitamin A molecule recycles back to plasma when it leaves plasma and goes to the slower or faster turning-over extravascular pool) can be estimated.

This approach is very powerful, but it is generally not possible in humans - especially in children - to collect the number of data points required to develop such a compartmental model (27 blood samples for the model described above). However, a 'super-child' model can be developed by collecting samples at selected times from many individuals to make up a complete sample set; this approach has been used in rat studies ${ }^{57}$. To illustrate the 'super-child' approach, data from Peruvian children of pre-school age were used ${ }^{16}$ (Fig. 6). At 3 days after oral administration of tetradeuterated retinyl acetate, the fraction of ingested dose remaining in plasma ranged from 0.01 to 0.0001 (Fig. 6a). That is, there was a 100-fold difference depending on either variation in absorption efficiency or in the extent of the total-body vitamin A pool
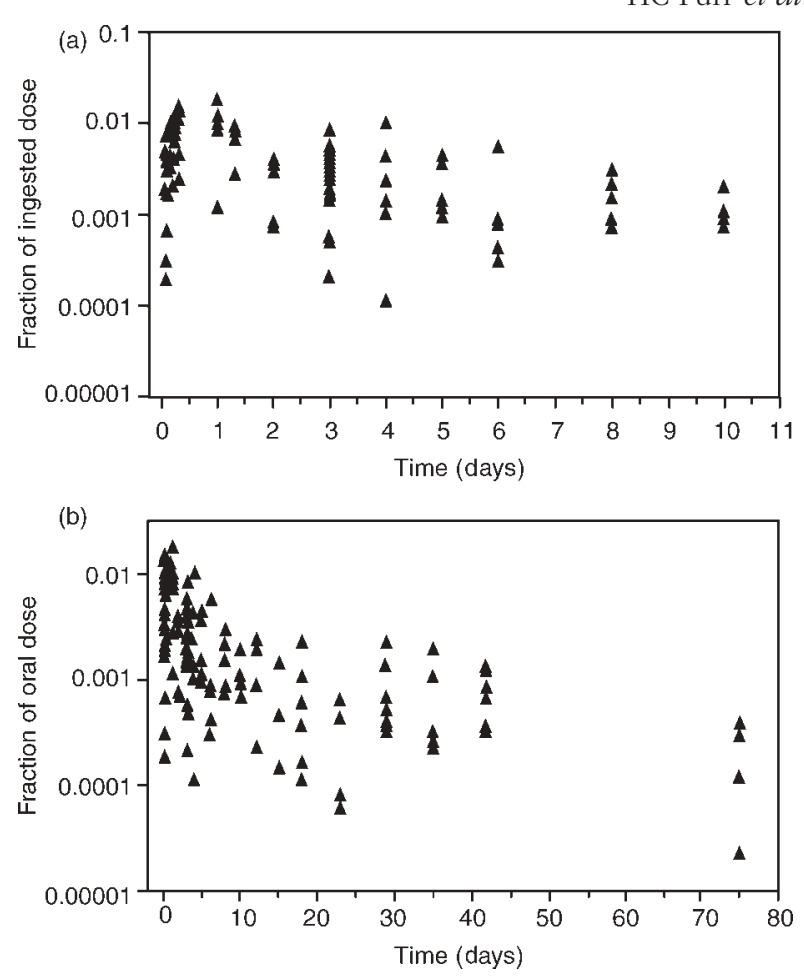

Fig. 6 'Super-child' model for development of mathematical model of vitamin A isotope dilution analysis in children: plasma response data following oral administration of tetradeuterated vitamin $A$ in multiple human subjects (data collected by Haskell et al. $^{16}$ ). (a) Data for the first 10 days following oral dosing; (b) data for 75 days following oral dose

size. It should be possible to categorise each child as having low, moderate or high vitamin A stores based on the 3-day sample, and data could be collected at two other times from each child to create the entire dataset as shown in Fig. 6b. Then, analysis would proceed as described above to develop a composite model of vitamin A metabolism in children at three levels of vitamin A status.

In summary, much more information can be obtained from stable isotope/isotope dilution studies with vitamin A by designing the study so that enough data are collected to apply model-based compartmental analysis (either on individual subjects or in a composite of many subjects). Using model-based compartmental analysis, it is possible to develop a compartmental description of whole-body vitamin A metabolism and quantitative estimates of rates of transfer between compartments, compartment sizes, the total traced mass, the disposal rate and dietary requirement, transit and residence times, recycling times and recycling number. Even if all the data cannot be obtained from the same subject, the 'super-child' approach can be used to combine data from several subjects into a larger dataset for modelling. As techniques to get reliable estimates of vitamin A absorption improve, and smaller amounts of isotope can be detected as the experiment progresses, model-based compartmental analysis holds the promise of helping us learn more about vitamin A 
status, requirements and metabolism in humans, and about outcomes of intervention programmes.

Several years ago, James Olson ${ }^{61}$ declared that isotope dilution techniques are a wave of the future in human nutrition. At that time the isotope dilution equation had just been shown to provide a good quantitative estimate of mean total-body vitamin A pool size, both for wellnourished Americans and for Bangladeshis with much lower vitamin A pool sizes. Since then, the usefulness of a shortened isotope dilution procedure for estimating totalbody vitamin A pool size has been demonstrated. Recent studies have also established that the DRD technique reveals differences in the vitamin A status of populations that may not be evident with the use of serum retinol measurements. Moreover, tracer methods can now be used to estimate the bioconversion and bioefficacy of carotenoids that is important for evaluating food-based interventions for improving vitamin A status. New and more sensitive methods that require a minute amount of serum, thereby avoiding the problems of perturbing tracee pools of vitamin A or of introducing potentially harmful amounts of radioactivity, continue to be developed. With the advent of tracer methods that can measure intervention impact, it may be possible to collect additional blood samples at different times from a relatively large number of individuals in order to build up a database. Applying the techniques of model-based compartmental analysis to this database will enable us to obtain other very useful information about vitamin A utilisation, dietary requirements and other aspects of whole-body vitamin A metabolism. Given these recent advances in mathematical modelling, in the technology of stable isotope analysis and in applications of isotope dilution, we can state that the wave of isotope dilution technology for assessment of human vitamin A status is indeed cresting.

\section{Acknowledgements}

This paper is the outcome of a consultation convened by the United States Agency for International Development's (USAID) Micronutrient Global Leadership project and the International Atomic Energy Agency. We thank Frances Davidson, Office of Health and Nutrition, USAID, for her interest and support and the International Life Sciences Institute's Human Nutrition Institute for hosting the meeting.

\section{References}

1 West KP Jr. Extent of vitamin A deficiency among preschool children and women of reproductive age. Journal of Nutrition 2002; 132(Suppl.): 2857S-66S.

2 van Agtmaal EJ, Amedee-Manesme O, Carlier C, Flores H, Furr HC, Keenum D, et al. A Brief Guide to Current Methods of Assessing Vitamin A Status. Washington, DC: International Life Sciences Institute, 1993; 1-36.

3 Tanumihardjo SA. Assessing vitamin A status: past, present and future. Journal of Nutrition 2004; 134(Suppl.): 290S-3S.
4 Rietz P, Vuilleumier JP, Weber F, Wiss O. Determination of the vitamin A body pool of rats by an isotopic dilution method. Experientia 1973; 29: 168-70.

5 Rietz P, Wiss O, Weber F. Metabolism of vitamin A and the determination of vitamin A status. Vitamins and Hormones 1974; 32: 237-49.

6 Hughes DR, Rietz P, Vetter W, Pitt GAJ. A method for the estimation of the vitamin A status of rats. International Journal for Vitamin and Nutrition Research 1976; 46: 231-4.

7 Bausch J, Rietz P. Method for the assessment of vitamin A liver stores. Acta Vitaminologica et Enzymologica 1977; 31: 99-112.

8 Shipley RA, Clark RE. Tracer Methods for In Vivo Kinetics. New York: Academic Press, 1972; 45-64.

9 Furr HC, Amedee-Manesme O, Clifford AJ, Bergen HR 3rd, Jones AD, Anderson DP, et al. Vitamin A concentrations in liver determined by isotope dilution assay with tetradeuterated vitamin A and by biopsy in generally healthy adult humans. American Journal of Clinical Nutrition 1989; 49: 713-6.

10 Haskell MJ, Handelman GJ, Peerson JM, Jones AD, Rabbi MA, Awal MA, et al. Assessment of vitamin A status by the deuterated-retinol-dilution technique and comparison with hepatic vitamin A concentration in Bangladeshi surgical patients. American Journal of Clinical Nutrition 1997; 66: $67-74$.

11 Haskell MJ, Mazumder RN, Peerson JM, Jones AD, Wahed MA, Mahalanabis D, et al. Use of the deuterated-retinoldilution technique to assess total-body vitamin A stores of adult volunteers consuming different amounts of vitamin A. American Journal of Clinical Nutrition 1999; 70: 874-80.

12 Raica N, Scott J, Lowry L, Sauberlich HE. Vitamin A concentration in human tissues collected from five areas in the United States. American Journal of Clinical Nutrition 1972; 25: 291-6.

13 Olson JA. Recommended dietary intakes (RDI) of vitamin A in humans. American Journal of Clinical Nutrition 1987; 45: 704-16.

14 Olson JA. Serum levels of vitamin A and carotenoids as reflectors of nutritional status. Journal of the National Cancer Institute 1984; 73: 1439-44.

15 Olson JA. Should RDA values be tailored to meet the needs of their users? Journal of Nutrition 1987; 117: 220-2.

16 Haskell MJ, Lembcke JL, Salazar M, Green MH, Peerson JM, Brown KH. Population-based plasma kinetics of an oral dose of $\left[{ }^{2} \mathrm{H}_{4}\right]$ retinyl acetate among preschool-aged, Peruvian children. American Journal of Clinical Nutrition 2003; 77 : 681-6.

17 Tang G, Gu X, Hu S, Xu Q, Qin J, Dolnikowski GG, et al. Green and yellow vegetables can maintain body stores of vitamin A in Chinese children. American Journal of Clinical Nutrition 1999; 70: 1069-76.

18 Tang G, Qin J, Hao LY, Yin SA, Russell RM. Use of a shortterm isotope-dilution method for determining the vitamin A status of children. American Journal of Clinical Nutrition 2002; 76: 413-8

19 Ribaya-Mercado JD, Solomons NW, Medrano Y, Bulux J, Dolnikowski GG, Russell RM, et al. Use of the deuteratedretinol-dilution technique to monitor vitamin A status of Nicaraguan schoolchildren $1 \mathrm{y}$ after initiation of the Nicaraguan national program of sugar fortification with vitamin A. American Journal of Clinical Nutrition 2004; 80: 1291-8.

20 Ribaya-Mercado JD, Solomons NW. Deuterated-retinoldilution approach for longitudinal monitoring of health and nutritional interventions involving vitamin A. Sight and Life Newsletter 2003; (2): 3-4.

21 Haskell MJ, Islam MA, Handelman GJ, Peerson JM, Jones AD, Wahed MA, et al. Plasma kinetics of an oral dose of 
$\left[{ }^{2} \mathrm{H}_{4}\right]$ retinyl acetate in human subjects with estimated low or high total body stores of vitamin A. American Journal of Clinical Nutrition 1998; 68: 90-5.

22 Ribaya-Mercado JD, Mazariegos M, Tang G, Romero-Abal ME, Mena I, Solomons NW, et al. Assessment of total body stores of vitamin A in Guatemalan elderly by the deuteratedretinol-dilution method. American Journal of Clinical Nutrition 1999; 69: 278-84.

23 Ribaya-Mercado JD, Solon FS, Dallal GE, Solomons NW, Fermin LS, Mazariegos M, et al. Quantitative assessment of total body stores of vitamin A in adults with the use of a 3-d deuterated-retinol-dilution procedure. American Journal of Clinical Nutrition 2003; 77: 694-9.

24 Ribaya-Mercado JD, Solon FS, Fermin LS, Perfecto CS, Solon JA, Dolnikowski GG, et al. Dietary vitamin A intakes of Filipino elders with adequate or low liver vitamin A concentrations as assessed by the deuterated-retinol-dilution method: implications for dietary requirements. American Journal of Clinical Nutrition 2004; 79: 633-41.

25 Hoppner K, Phillips WEJ, Erdody P, Murray TK, Perrin DE. Vitamin A reserves of Canadians. Canadian Medical Association Journal 1969; 101: 84-6.

26 Adams WR, Green MH. Prediction of liver vitamin A in rats by an oral isotope dilution technique. Journal of Nutrition 1994; 124: $1265-70$.

27 Ribaya-Mercado JD, Solon FS, Solon MA, Cabal-Barza MA, Perfecto CS, Tang G, et al. Bioconversion of plant carotenoids to vitamin A in Filipino school-aged children varies inversely with vitamin A status. American Journal of Clinical Nutrition 2000; 72: 455-65.

28 West CE, Castenmiller JJ. Quantification of the 'SLAMENGHI' factors for carotenoid bioavailability and bioconversion. International Journal for Vitamin and Nutrition Research 1998; 68: 371-7.

29 Tanumihardjo SA. Factors influencing the conversion of carotenoids to retinol: bioavailability to bioconversion to bioefficacy. International Journal for Vitamin and Nutrition Research 2002; 72: 40-5.

30 Russell RM, Ross AC, Trumbo PR, West KP. Retinol equivalency ratio of $\beta$-carotene. Journal of Nutrition 2003; 133: 2915-6.

31 West CE, Eilander A, van Lieshout M. Reply to Russell et al. Journal of Nutrition 2003; 133: 2917.

32 Grusak M. Intrinsic stable isotope labeling of plants for nutritional investigations in humans. Journal of Nutritional Biochemistry 1997; 8: 164-71.

33 Haskell MJ, Jamil KM, Hassan F, Peerson JM, Hossain MI, Fuchs GJ, et al. Daily consumption of Indian spinach (Basella alba) or sweet potatoes has a positive impact on total body vitamin A stores of Bangladeshi men. American Journal of Clinical Nutrition 2004; 80: 705-14

34 Parker RS, Swanson JE, You CS, Edwards AJ, Huang T. Bioavailability of carotenoids in human subjects. Proceedings of the Nutrition Society 1999; 58: 155-62.

35 Tang G, Qin J, Dolnikowski GG, Russell RM, Grusak M. Vitamin A value of spinach and carrots as assessed using a stable isotope reference method. FASEB Journal 2004; 18: A157.

36 McEvoy FA, Lynn WS. Chloroplast membrane proteins. II. Solubilization of the lipophilic components. Journal of Biological Chemistry 1973; 248: 4568-73.

37 Goodwin T. The Biochemistry of the Carotenoids. London: Chapman and Hall, 1980.

38 Wang Y, Xu X, van Lieshout M, West CE, Lugtenburg J, Verhoeven MA, et al. A liquid chromatography-mass spectrometry method for the quantification of bioavailability and bioconversion of $\beta$-carotene to retinol in humans. Analytical Chemistry 2000; 72: 4999-5003.

39 van Lieshout M, West CE, Muhilal, Permaesih D, Wang Y, Xu $\mathrm{X}$, et al. Bioefficacy of $\beta$-carotene dissolved in oil studied in children in Indonesia. American Journal of Clinical Nutrition 2001; 73: 949-58.

40 van Lieshout M, West CE, van de Bovenkamp P, Wang Y, Sun Y, Van Breemen RB, et al. Extraction of carotenoids from feces, enabling the bioavailability of $\beta$-carotene to be studied in Indonesian children. Journal of Agricultural and Food Chemistry 2003; 51: 5123-30.

41 Edwards AJ, You CS, Swanson JE, Parker RS. A novel extrinsic reference method for assessing the vitamin A value of plant foods. American Journal of Clinical Nutrition 2001; 74: 348-55.

42 Yao L, Liang Y, Trahanovsky WS, Serfass RE, White WS. Use of a ${ }^{13} \mathrm{C}$ tracer to quantify the plasma appearance of a physiological dose of lutein in humans. Lipids 2000; 35: 339-48.

43 Parker RS, Brenna JT, Swanson JE, Goodman KJ, Marmor B. Assessing metabolism of $\beta-\left[{ }^{13} \mathrm{C}\right]$ carotene using highprecision isotope ratio mass spectrometry. Methods in Enzymology 1997; 282: 130-40.

44 Kelm MA, Flanagan VP, Pawlosky RJ, Novotny JA, Clevidence BA, Britz SJ. Quantitative determination of ${ }^{13} \mathrm{C}-$ labeled and endogenous $\beta$-carotene, lutein, and vitamin $\mathrm{A}$ in human plasma. Lipids 2001; 36: 1277-82.

45 Kurilich AC, Britz S, Clevidence BA, Novotny JA. Isotopic labeling and LC-APCI-MS quantification for investigating absorption of carotenoids and phylloquinone from kale (Brassica oleracea). Journal of Agricultural and Food Chemistry 2003; 51: 4877-83.

46 Lienau A, Glaser T, Tang G, Dolnikowski GG, Grusak MA, Albert K. Bioavailability of lutein in humans from intrinsically labeled vegetables determined by LCAPCI-MS. Journal of Nutritional Biochemistry 2003; 14 $663-70$.

47 Dueker SR, Lunetta JM, Jones AD, Clifford AJ. Solid-phase extraction protocol for isolating retinol- $\mathrm{d}_{4}$ and retinol from plasma for parallel processing for epidemiological studies. Clinical Chemistry 1993; 39: 2318-22.

48 Tang G, Andrien BA, Dolnikowski GG, Russell RM. Atmospheric pressure chemical ionization and electron capture negative chemical ionization mass spectrometry in studying $\beta$-carotene conversion to retinol in humans. Methods in Enzymology 1997; 282: 140-54.

49 Guo ZK, Luke AH, Lee WP, Schoeller D. Compound-specific carbon isotope ratio determination of enriched cholesterol. Analytical Chemistry 1993; 65: 1954-9.

50 Tanumihardjo SA. Vitamin A status assessment in rats with ${ }^{13} \mathrm{C}_{4}$-retinyl acetate and gas chromatography/combustion/ isotope ratio mass spectrometry. Journal of Nutrition 2000; 130: 2844-9.

51 Dueker SR, Lin Y, Buchholz BA, Schneider PD, Lame MW, Segall $\mathrm{HJ}$, et al. Long-term kinetic study of $\beta$-carotene, using accelerator mass spectrometry in an adult volunteer. Journal of Lipid Research 2000; 41: 1790-800.

52 Lemke SL, Dueker SR, Follett JR, Lin Y, Carkeet C, Buchholz $\mathrm{BA}$, et al. Absorption and retinol equivalence of $\beta$-carotene in humans is influenced by dietary vitamin A intake. Journal of Lipid Research 2003; 44: 1591-600.

53 Green MH, Green JB. Experimental and kinetic methods for studying vitamin A dynamics in vivo. Methods in Enzymology 1990; 190: 304-17.

54 Green MH, Green JB. The application of compartmental analysis to research in nutrition. Annual Review of Nutrition 1990; 10: 41-61.

55 Berman M, Weiss MF. SAAM Manual. DHEW Publication No. 78-180. Washington, DC: US Government Printing Office, 1978.

56 Wastney ME, Patterson BH, Linares OA, Greif PC, Boston RC. Investigating Biological Systems Using Modeling. Strategies and Software. San Diego, CA: Academic Press, 1999; 1-370. 
57 Green MH, Uhl L, Green JB. A multicompartmental model of vitamin A kinetics in rats with marginal liver vitamin A stores. Journal of Lipid Research 1985; 26: 806-18.

58 Lewis KC, Green MH, Green JB, Zech LA. Retinol metabolism in rats with low vitamin A status: a compartmental model. Journal of Lipid Research 1990; 31: 1535-48.

59 Tang G, Qin J, Dolnikowski GG, Russell RM. Short-term (intestinal) and long-term (postintestinal) conversion of $\beta$-carotene to retinol in adults as assessed by a stable-isotope reference method. American Journal of Clinical Nutrition 2003; 78: 259-66.

60 Wang Z, Zhao X, Yin S, Russell RM, Tang G. $\beta$-Carotenevitamin A equivalence in Chinese adults assessed by an isotope dilution technique. British Journal of Nutrition 2004; 91: $121-3$.

61 Olson JA. Isotope-dilution techniques: a wave of the future in human nutrition. American Journal of Clinical Nutrition 1997; 66: 186-7. 